poultice: He next relates two cases of inflammation of the fingers, which were treated by incision, caustic, and poultices. There are also a few remarks on the fungons nlcer of the navel in infants, which the anthor renoves by the scissors; and after applying the caustic, defends the part from the air by gold-beater's skin. Some observations on the housemaid's knee and tinea capitis, of no particular importance, conclude the section.

When wounds and ulcers are small and superficial, and seated in parts which have little cellular membrane, there can be no doubt of the efficacy of the plans of treatment which the author proposes; but when an ulcer is vely large, or where from its locality it cannot possibly remain undisturbed, as between the toes, or in cases attended with much inflammation or adema, the treatment by eschar must not be thought of. The practice is likely to succeed best with those sores that are small and indolent, which, iudeed, every surgeon has been accustomed to touch with caustic. Mr.H. has found it inap. plicable in extensive lacerations, and the greater proportion of incised wounds.He has also failed in his attempts to heal scrofulous sores by the adhesive eschar. $I_{1}$ erysipelatous inflammation, where $\checkmark$ asicles are formed, and in recent burns, the caustic does harm; boils, also, are aggravated rather than diminished by it. But he has undoubtedly proved, that canstic is available in more cases than surgeons have hitherto supposed, and that, where its individual powers are in. sufficient, it is an useful adjuvant.

The reader will observe that we have made a very copious analysis of the volume.

\section{MUSEUM AT ST. THOMAS'S HOSPITAL.}

Mr. Green, in his "Reply" to the "Memorial' of Messrs. Key and Cooper, has the following paragraph :

"The true statement is, that Sir Astley Cooper, and not $\mathrm{Mr}$. Cline, received 1000l. from me for the moiety of the Museum. Mr. Cline, senior, did, indeed, receive 1000l. from Sir Astley Cooper at the same time, but it was, as the executor of Mr. Cline, junior, according to articles of agreement. It is upon this transaction that the misrepresentation is founded, that Mr. Cline, senior, received 2000i.; the fact being, that he received the last mentioned 1000l. only as an executor: and, according to the terms of the same agreement, Sir Astley Cooper is now entitled to reccive $1000 \mathrm{l}$. from me. This being paid, Sir Astley Cooper, indeed, will have received $2000 l$. but $\mathrm{Mr}$. Cline, senior, in his own right, only 1006l." Pamphlet p. 54.

No sooner was this statement publish$e d$, than it elicited some expressions from Mr. B. Cooper of rather an unqualified nature, they will be found in a letter addressed to Sir A. Cooper by Mr. Green, which we will here insert :

"46, Lineoln's Inn Fields, Nov. 6th, 1825.

Sir,-Mr. Bransby Cooper made, yesterday, in the Theatre of Guy's Gospital, a public statement, "That Sir Astley Cooper never received, either directly or indirectly, a thousand pounds from me for a moiety of the Museum; and that there still rests a lie between $\mathrm{Mr}$. Bransby Cooper and myself; and that it is not with him, so help him God!'

Mr. Bransby Cooper acknowledges these words, and an explanation having: been requested by me of the imputation contained in them, he has made the following statement: -

- Mr. Bransby Cooper can in two points falsify the accusations made by Mr. Green in his reply to Mr. B. Cooper's memorial, namely, with respect, to Sir A. Cooper's sver having received one farthing from any one for the Museum, or any part of the Musenm, I pled ge myself he never did, notwithstanding $\mathrm{Mr}$. Green's assertion, that Sir $\boldsymbol{A}$. Cooper, and not $\mathrm{Mr}$. Cline, received that $1000 l$.'

"The second point on which Mr. B. Cooper contradicts Mr. Green's assertion, is with respect to his denial of having received a conditional letter as to $\operatorname{Sir} A$. 
Cooper's resignation. In answer to that, Mr. B. Cooper says, that he himself gave Mr. Green that letter ; that Mr. Gieen read it, and said, that had he had himself to propose conditions, they would have accorded with those of Sir A. Cooper, with respect to the division of the Huseum; that he reatdily acceded to the $\mathrm{m}$; and in consequence of this concession of $\mathrm{Mr}$. Green's, Sir A Cooper resigned.'

Now, Sir, as it will not be believed that these assertions conld have been hazarded withont your sanction or anthurity; and, as a full explanation has now become as necessary to your character as to mine, I beg the favour of an explicit answer to two questions. Did you ever receive 1000l. firom me for a moiety of the Museum? Did you write me a letter, saying you would not resign, but upon condition that your share of the Musenm should become the property of your Nephews. I am, Sir,

Yonr obedient servant,

(Signed) Joseph HËry GreEn. Sir A. Cooper, Bart."

In confirmation of the original assertion" that he had paid the 1000l, to Sir A. Cooper and not to Mr. Cline," Mr. Green, at page 11 of his pampblet, thus writes:

"The fact is, that your payment of the sum due from you to Mr. H. Cline's ex:cutor, was posterior, by above twelve months, to your receipt of the 1000 l. from me: and in proof of which the receipts themselves are amexed:

-Received, 3d August, 1820, of $\mathrm{Mr}$. Joseph Henry Green, one thousand pomids, in full consilieration for one half of the collection of Anatomical Preparations, and Preparations of Morbid Parts, contained in the Museum of St. Thomas's Hospital, together with the Drawings and Apparalus used for the teaching of Aua. tomy in the same Hospital.
(Signed)
Asthey Cooprar.'

- Received, 2jth Jauuary, 1822, of Sir Astley Cooper, Bart., one thousanr pounds, in full consideration for the moiety of the collection of Anatomical Preparations in St. Thomas's Hospital, the property of the late Henty Clune, jun., accorting to articles of ayreetivent respecting the same, dated 17 th Nov. 1811.

$$
\text { (Signed) Henny Curvf, }
$$
Eیecutor.'

' I admit the above to be a correct copy of the Receipt.

Dec. 2d 1325."'
Mr. Green's magnanimous and spirited conduct on being charged with uttering a lie, is entilled to universal approbation, and we trust it will for ever furnish a moral and salutary lesson to those mock heroes and spurious defenders of honour, called duellists, for whase be. nefit we will here briefly describe Mr. Green's panacea for wounded honour:should $\mathrm{A}$. give B. the lie, B. is to demand an explanation, and if A. persist in the accusation, B. must then urite to C., ask an indifferent question or two, and the affair immediately terminates to the satisfac. tion of all parties. We have been highly gratified with the simplicity and manli. ness of this preceeding.

How are the contradictions contained in the above statements regarding the payment of the 1000l. to be reconciled? Mendacity of no very moderate extent must exist on one sile or the otherSir Astley Cooper and his Nephers assert that Mr. Green paid the 1000l to Mr. Cline. Mr. Green, on the contrary, as positively states, that he paid the nto. ney to Sir A. Cooper, and to prove his accuracy, has published the receipt given by Sir A. Cooper. How then, are we to arrive at the truth? This we shall see presently. We will first relate the circumstances connected witl this money business as they actually occurred. On the death of Mr. H. Cline, Mr. Cline sen. was entitled to $1000 l$. for a moiety of the Museum, at this time an arrangement was entered into, that Mr. Green should be. come Sir A. Cooper's partner in the Mu. seum. Mr. Green tendered to Sir A. Cooper the above 1000l, in payment for the moiety previously held by Mr. $\mathrm{H}$. Cline. When Mr. Green offered this money to Sir A. Cooper, the worthy B. ronet refinsed to take it, and advised Mr. Green to present it to Mr. Cline, obser. ing at the same time, that as Mr. Cline was his Uncle, he probably wonld not re. 
ceive it from lim. Subsequently, Mr. Green acquainted Sir A. Cooper, that Mr. Cline would not receive the cash unless accompanied by a reccipt from him. "Well," said Sir A. with his usual frankness, "I will give you a receipt," which he actually did; Mr. Green at the same time retaining the money for the purpose of handing it over to $\mathrm{Mr}$. Cline. Eig hteen months alter this took place, the receipt from $\mathrm{Mr}$. Cline was sent to Sir A. Cooper, during which period the money had not been in the hands of Sir $A$. Cooper for one moment, or any of his agents.

With a knowledge of these facts, was it not a "contemptible artifice" on the part of Mr. Green, to publish the above receipts without any explanation of the circumstances under which they were given? The thing speaks for itself. Such diplicity is disgusting to every honourable mind.

It may be alleged that this statement of facts is equally unsupported with the assertions of $\mathrm{Mr}$. J. H. Green; that it is merely denial opposed to denial, and it may also be asked how can the truth be indisputably ascertained? We will acquaint Mr. Green-by his procuring a letter from Mr. Cline, stating when he received the thousand pounds, and from whon he received $i t$. We are much surprised that the necessity of obtaining such a document did not occur to $\mathrm{Mr}$. Green at the very outset of the controversy, and as it appears to have entirely escaped his notice, we feel great pleasure in directing his attention to a circumstance which may hereafter prove of the highest consequence to his reputation.

We will reserve a niche for the insertion of $\mathrm{Mr}$. Cline's letter in our ensuing number.

\section{HOSPITAL REPORTS.}

\section{GUY'S HOSPITAL.}

\section{Carcinomatous affection of the Pharynx.}

The pharynx, according to the anthority of Sir Astley Cooper, is not unfrequently the seat of cancerous disease, of which the following case is said to be an example. There is, however, one curious and almost inexplicable circumstance (as will appear from the report) connected with this case, namely, the entire absence of lancinating pain, which is in general regarded as one of the essential characteristics of cancerous diseaze in any part of the body.

Case.-William Cox, aged 60, a labouring man from the country, and of temperate habits, was admitted on 9 th of November, under the care of $\mathrm{Mr}$. Key, with disease of the throat, which lie stated to be of many months' standing. He complained of much difficulty in swallowing, and also of not being able to breathe through the nostrils, which circumstances alone, but more especially the former, induced him to seek relief; for he said that he was entirely fiee from pain, and indecd his appearance did not falsify this assertion. (In examining the throat, it was found that the natural appearance of the parts about the fauces was so completely altered by disease, as to render it almost impossible to distingnish the original parts, and it is equally impossible to convey an adequate idea of the change thus produced. The pillars of the fauces and tonsils on each side were partly destroyed, and those portions which remained were converted into a rugged cartilaginous substance, the back of the pharynx converted into the same scirrhous substauce, and also the nesophagus. The disease had in like manner extended to the soft palate, in the middle of which was a fissure, and on each side of this the parts had the hardness just described. There was no distinct or positive appearance of breach of surface, except on the velum, and even this $M r$. Key considered dubious. The patient has now been in the hospital upwards of two months, but little change has taken place in the appearance of the parts, \&c. The man states that he is quite tree from pain. He has used a common acid gargle, and taken five grains of Plummer's pils at bed time.

There is one circumstance which it is material to mention, namely, that the 